\title{
REVIEW
}

\section{Obesity: diagnosis, prevention, and treatment; evidence based answers to common questions}

\section{J J Reilly, M L Wilson, C D Summerbell, D C Wilson}

Arch Dis Child 2002;86:392-395

Paediatric obesity is now common in the UK, as in other developed countries. A literature search was conducted and evidence based answers to five frequently answered questions sought. Recommendations for diagnosis are given. Although there is no conclusive evidence that the condition is preventable, a number of treatment approaches are promising.

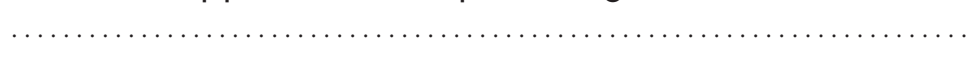

See end of article for authors' affiliations

.....................

Correspondence to: Dr J J Reilly, University of Glasgow Department of Human Nutrition, Royal Hospital for Sick Children, Glasgow G3 8SJ, Scotland, UK; iir2y@clinmed.gla.ac.uk

\begin{abstract}
$\Lambda^{n}$ n epidemic of childhood obesity occurred recently across the developed world, ${ }^{12}$ and in many developing countries, ${ }^{3}$ following an epidemic of adult obesity. There is increasing concern over the likely clinical and public health implications of the epidemic. ${ }^{45}$ However, childhood obesity is difficult to treat and there remains a great deal of uncertainty surrounding its prevalence, diagnosis, prevention, and treatment. The uncertainty and confusion has led to wide variation in clinical practice. The present review aims to provide evidence based answers to five frequently asked questions: How should obesity be diagnosed? What is its prevalence in the UK? Is it preventable? Is it treatable? How should it be managed?
\end{abstract}

\section{METHODS}

\section{Literature searching}

We searched for systematic reviews and metaanalyses using Medline, Embase, Cinahl, Healthstar, the Cochrane Library, and the internet from January 1991 to April 2000. Searching for other study designs used the same databases from January 1981 to June 2000 and was supplemented by manual searching of reference lists of all identified papers, and by manual searching of reference lists of key specialist journals from January 1997 to June 2000. We identified a Cochrane review on interventions for prevention of obesity in children, ${ }^{6}$ a protocol for a Cochrane review on interventions for treatment of obesity in children, ${ }^{7}$ and a systematic review which included children but focused largely on adults. ${ }^{8}$ We compared search results from the present review as a check on the quality of literature searching.

\section{Evidence appraisal}

Evidence appraisal used methodology described elsewhere.' In summary, evidence from the searches was identified using inclusion criteria specific to each question. Two reviewers then appraised each paper independently and agreed on an evidence level and methodological quality rating using the hierarchy of study types published elsewhere.' In brief, this hierarchy consisted of the following.

- Evidence level 1, systematic reviews and metaanalyses of randomised controlled trials (RCTs); RCTs

- Evidence level 2, non-randomised intervention studies, observational/cohort studies

- Evidence level 3, non-experimental studies, surveys

- Evidence level 4, expert opinion.

Following published criteria, ${ }^{9}$ studies were rated as : ++ (all or most methodological criteria met, low risk of bias); + (some criteria not fulfilled or study inadequately described, but low risk of bias); - (few or no criteria fulfilled, high risk of bias). Grades of recommendations (A-D) are based on the strength of the supporting evidence, taking into account its overall level and the considered judgement of the authors.

\section{RESULTS}

Question 1: How should obesity be diagnosed and assessed?

Inclusion criteria

Studies were included: if they assessed the ability of the body mass index (BMI) to identify children with high body fat percentage; if they assessed relations between BMI centile and obesity associated morbidity (for example, cardiovascular risk factors); or if they compared subjective and objective assessment of obesity. Expert committee recommendations were also included .

\section{Use of the BMI}

Cross and colleagues ${ }^{10}$ (table 1) found that (subjective) clinical judgements were inadequate, even when made by experienced observers (evidence level 3). Expert committees have consistently recommended an objective approach (grade $D$ ), based on the body mass index centile (grade B) (table 1). Many other authors (in editorials, for example) have also recommended the BMI, but these forms of evidence were not formally appraised. The main advantages of BMI are that it is practical, objective, provides a degree of consistency with adult practice, and is biologically meaningful.

The BMI is lower in children/adolescents than in adults, so adult obesity definitions (such as BMI >30.0) should not be applied. The BMI

Abbreviations: $B M I$, body mass index; RCT, randomised controlled trial 
Table 1 Summary of evidence appraised, questions 1-4

\begin{tabular}{|c|c|c|}
\hline Study: first author, year & Reference & $\begin{array}{l}\text { Evidence } \\
\text { level }\end{array}$ \\
\hline \multicolumn{3}{|c|}{ Question 1: How should obesity be diagnosed and assessed? } \\
\hline SE Barlow, 1998 & 13 & 4 \\
\hline JH Himes, 1994 & Am J Clin Nutr 59:307-16 & 4 \\
\hline EME Poskitt, 1995 & Acta Paediatr 84:961-3 & 4 \\
\hline C Power, 1997 & Int J Obes 21:507-26 & $2++$ \\
\hline MC Bellizzi, 1999 & Am J Clin Nutr 70:173-177s & 4 \\
\hline M de Onis, 1996 & Am J Clin Nutr 64:650-8 & 4 \\
\hline JH Cross, 1995 & 10 & 3 \\
\hline JJ Reilly, 1999 & Int J Obes 23:217-19 & 3 \\
\hline JT Warner, 1997 & Ann Hum Biol 24:209-15 & 3 \\
\hline JJ Reilly, 2000 & 14 & $2+$ \\
\hline LB Sardinha, 1999 & Am J Clin Nutr 70:1090-5 & 3 \\
\hline JH Himes, 1999 & Int J Obes 23:s18-s21s & 3 \\
\hline JD Marshall, 1991 & Hum Biol 63:137-53 & 3 \\
\hline R Malina, 1999 & Am J Clin Nutr 70: s131-s136 & 3 \\
\hline F Schaefer, 1998 & Int J Obes 22:461-9 & 3 \\
\hline R Lazarus, 1996 & Am J Clin Nutr 63:500-6 & 2 \\
\hline \multicolumn{3}{|c|}{ Question 2: What is the prevalence of obesity in the UK? } \\
\hline JJ Reilly, 1999 & 1 & 3 \\
\hline JJ Reilly, 1999 & BM 319:1039 & $2+$ \\
\hline SJ Kinra, 1999 & 22 & $2+$ \\
\hline \multicolumn{3}{|c|}{ Question 3: Is childhood obesity preventable? } \\
\hline RV Luepker, 1996 & JAMA 275:768-76 & $1+$ \\
\hline SL Gortmaker, 1999 & Arch Pediatr Adolesc Med 153:409-18 & $1+$ \\
\hline \multicolumn{3}{|c|}{ Question 4: Is childhood obesity treatable? } \\
\hline LM Mellin, 1987 & J Am Diet Assoc 87:333-8 & $1+$ \\
\hline LH Epstein, 1995 & Health Psychol 14:109-15 & $1+$ \\
\hline LH Epstein, 2000 & Arch Pediatr Adolesc Med 154:220-6 & $1+$ \\
\hline
\end{tabular}

changes during childhood and differs between boys and girls, so age and sex specific reference data (centile cut off points on charts) are necessary to interpret the measurement. For the UK, national reference data for BMI are available. ${ }^{11}$ These data represent the BMI of British children in 1990 and are widely available in the form of centile charts. ${ }^{112}$

One important consideration with BMI is its ability to successfully classify overweight/obese children and adolescentsthat is, its sensitivity and specificity in identification of the fattest children. Nine studies (evidence levels $2+$ to 3 ) addressed this question (table 1) by making direct measurements of body fatness and testing the ability of cut offs applied to the upper end of the BMI distribution to correctly classify the fattest children. These concluded that a BMI cut off in the upper end of the BMI range (for example, above the 85th centile) was specific for obesity (low false positive rate). Expert committees have viewed this as the main consideration when diagnosing obesity as it avoids problems associated with stigmatising children or providing unnecessary treatment. ${ }^{13}$ However, the magnitude of the false negative problem depends on the cut off which is used. When using BMI >91st centile on the UK 1990 charts for British children, sensitivity is moderately high and specificity high. ${ }^{14}$ In practice, clinical assessment of obesity in British children using British BMI centile charts will be robust provided that an appropriate cut off (for example, BMI >98th centile) is used. Serial measures of BMI, plotted on the chart, can assess changes over time. In epidemiological use, other cut offs (for example, 85 th centile for overweight and 95th centile for obesity) will remain common. ${ }^{213}$ BMI cut offs above the 85 th centile are also clinically meaningful. A good deal of evidence shows that children with high BMI are at greatest risk from the morbidity associated with childhood obesity. This includes studies showing associations of BMI with morbidity in childhood, ${ }^{15}$ with persistence of obesity into adulthood, ${ }^{16}$ and with presence and clustering of cardiovascular risk factors (evidence level $2++$ to $2+) \cdot{ }^{17-19}$
"International" BMI reference data have been proposed recently for global comparisons of childhood obesity prevalence. ${ }^{20}$ One British study reported improved screening ability (higher sensitivity; high specificity) when national (UK) reference data were used, compared to use of the international reference data. ${ }^{14}$ Sensitivity of the definition of obesity using the international reference data differed significantly between the sexes, with low sensitivity in girls and extremely low sensitivity in boys. ${ }^{14}$ International BMI cut offs for BMI in children have not been related to obesity related morbidity in childhood. They require further testing, with evidence of external validity, before they are adopted. A more extensive discussion of the use of international reference data has been published elsewhere. ${ }^{21}$

\section{Question 2: What is the prevalence of paediatric obesity in the UK? \\ Inclusion criteria}

Studies were included if they used a definition of obesity based on BMI, in British children. This included nationally representative surveys, regional/local surveys, and cohort studies (table 1).

\section{Prevalence estimates}

All three studies identified by the original search indicated a higher prevalence of obesity than expected (evidence level $2+$ to 3) (table 1). Only one study was based on a nationally representative sample : obesity prevalence ranged from $11 \%$ in 6 year olds to 17\% in 15 year olds in England in 1996. ${ }^{1}$ This evidence shows a notable increase in overweight and obesity prevalence from the early 1990s in the UK. All studies concluded that risk increases with age during childhood and adolescence (evidence level $2+$ to 3 ). One study found that obesity prevalence increased with increasing social deprivation ${ }^{22}$ (evidence level 3). Obesity prevalence was generally not notably different between boys and girls (evidence level $2+$ to 3 ). 
Question 3: Is childhood obesity preventable? Inclusion criteria

For inclusion, papers had to report a randomised controlled trial (RCT) study design, in a study population drawn from non-clinical samples (that is, subjects from community, school, or nursery), and had to include an objective weight related outcome measure such as BMI or weight change. Studies of both obesity prevention and treatment (question 4) were only included if outcome measures were obtained at least 12 months after the start of the intervention, on the grounds that short term lifestyle change might not be sustainable in the longer term, so short term studies carried a high risk of bias. For questions 3 and 4, RCTs with a negative quality rating were not used as the basis of recommendations and excluded from this review, though reference details and evidence tables are available from the authors.

\section{Evidence appraisal and summary}

Three RCTs were identified, but only two studies met our inclusion criteria (Gortmaker et al, 1999; Luepker et al, 1996; table 1). Both studied large samples of schoolchildren, and were of high methodological quality. In both, interventions were complex, with focus on: diet; physical inactivity (targeting reduced TV viewing); physical activity; involvement of schools with changes to curricula; involvement of family. Both interventions were resource intensive, and from the USA. This probably limits the generalisability of their conclusions. Luepker et al (1996) found no significant differences in weight related outcome indices at three year follow up. Gortmaker et al (1999) reported that obesity risk was significantly reduced in girls, but not in boys. In summary, there is some doubt as to whether obesity is preventable in school age children, using currently available intervention strategies (evidence level $1+$ ). Further research is indicated, though more recent evidence, published after the present literature review had been completed, is not promising. ${ }^{23}$

\section{Question 4: Is childhood obesity treatable?}

\section{Inclusion criteria}

We included only RCTs, with a study population of children who were defined as obese, and who were followed for at least 12 months post-intervention, for the reasons given above.

\section{Evidence appraisal and summary}

We identified 16 studies which met our inclusion criteria. Of these, 12 were from the USA and six were from the same research group. No evidence on drug treatment or residential treatment ("fat camps") met our criteria. Only three of the 13 trials did not have major methodological flaws, and these were rated as evidence level $1+$ (summarised in table 1$)$. Most of the other trials were older studies carried out before the recent development of guidelines for conduct and reporting of RCTs. All were graded as 1- (high risk of bias).

The three high quality studies all delivered complex interventions aimed at achieving long term behavioural change, were resource intensive, and were conducted in specialist clinics (two from the same research group). The studies are therefore difficult to summarise, and there are doubts about their generalisability. In each case diet was combined with lifestyle interventions intended to increase physical activity levels, and families were involved. Increases in physical activity were targeted by a focus on reduction in sedentary behaviour (particularly TV viewing), and/or lifestyle physical activity (for example, walking). In all three studies, treatment significantly reduced indices of overweight/obesity (evidence level $1+$ ). In the absence of clearly generalisable evidence on treatment strategies, further research is indicated. Expert committee recommendations therefore remain useful.
Box 1: Guidance on management of obese children and adolescents*

Who should be treated?

- Children defined objectively as obese (BMI >98th centile, UK 1990 reference data)

- Only children where the child and family appear willing to make the necessary lifestyle changes

(evidence level 4)

What should the aims of treatment be?

- Resolve comorbidity, if present

- Aim at behavioural changes, not weight loss: healthier eating; more activity lat least 30 minutes of moderate activity, e.g. brisk walking, most days; less inactivity (i.e., $<2$ hours TV viewing and computer game use/day)

- Involve the family in monitoring eating and activity and in making the necessary changes

(evidence level 4)

Who should be referred?

- Children likely to have serious comorbidity (e.g. sleep apnoea)

- Children with possible pathological (e.g. endocrine) cause of obesity (e.g. severe obesity in the under $2 \mathrm{~s}$; obesity in the presence of short stature)

(evidence level 4)

*From US expert committee recommendations, summarised by Barlow and Dietz. ${ }^{13}$

These recommend focus on diet and control of sedentary behaviour, with family involvement. ${ }^{13}$

\section{Question 5: What do I do with the obese child or adolescent?}

This question has three components: Who should be treated? What should treatment aims be? Who should be referred? Recommendations from expert committees/consensus statements were the only evidence which was identifiable to answer these questions (evidence level 4 ). These are summarised in box 1 and are widely available via the internet. ${ }^{13}$ Evidence based guidelines from the UK (Scottish Intercollegiate Guidelines Network), based in part on this systematic review, should be available in 2002 .

\section{CONCLUSIONS}

(1) Paediatric obesity is now common in the UK, as in other developed countries.

(2) Obesity should be diagnosed using the BMI centile on the UK 1990 reference charts (Child Growth Foundation, London, UK; printed by Harlow Printing, South Shields, UK), and this should also be used to monitor changes in weight status (grade of recommendation B).

(3) There is no conclusive evidence that childhood obesity is preventable at present, but more research is required. A number of approaches to treatment are promising, notably the control of sedentary behaviour such as TV viewing. These merit further evaluation.

\section{ACKNOWLEDGEMENTS}

We thank Francesca Chappell for her assistance with literature searching. Work for this review contributed to the Scottish Intercollegiate Guidelines Network guideline on "Obesity in Children and Young People". 


\section{Authors' affiliations}

J J Reilly, University of Glasgow Department of Human Nutrition, Royal Hospital for Sick Children, Glasgow G3 8SJ, Scotland, UK

M L Wilson, D C Wilson, University of Edinburgh Department of Child Life and Health, Royal Hospital for Sick Children, 9 Sciennes Road, Edinburgh EH9 ILF, Scotland, UK

C D Summerbell, University of Teesside, School of Health and Social Care, Middlesborough TS1 3BA, UK

\section{REFERENCES}

1 Reilly JJ, Dorosty A. Epidemic of obesity in UK children. Lancet 1999;354:1874-5.

2 Troiano RP, Flegal KM. Overweight children and adolescents: description, epidemiology, and demographics. Pediatrics 1998; 101:497-504

3 Martorell R, Khan LK, Grummer-Strawn LM. Overweight and obesity in pre-school children from developing countries. Int J Obes 2000;24:959-67.

4 Koplan JP, Dietz WH. Caloric imbalance and public health policy. JAMA 1999;282:1579-81.

5 Sokol RJ. The chronic disease of childhood obesity: the sleeping giant has awakened. J Pediatr 2000;136:711-13.

6 Campbell K, Waters E, O'Meara S, et al. Interventions for preventing obesity in children. Review published in Cochrane Library 2001, Issue 1

7 Summerbell CD, Waters E, Edmunds L, et al. Interventions for treating obesity in children. Protocol first published in the Cochrane Library 1999, Issue 4.

8 Glenny A, O'Meara S, Melville A, et al. The treatment and prevention of obesity: a systematic review of the literature. Int J Obes 1997;21:715-37.

9 Harbour R, Miller J. A new system for grading recommendations in evidence based guidelines. BMV 2001;323:334-6.

10 Cross JH, Holden C, MacDonald A, et al. Clinical examination compared with anthropometry in evaluating nutritional status. Arch Dis Child 1995;72:60-1.
11 Cole TJ, Freeman JV, Preece MA. Body mass index reference curves for the UK, 1990. Arch Dis Child 1995;73:25-9

12 Wright CM, Booth IW, Buckler JMH, et al. Growth reference charts for use in the UK. Arch Dis Child 2002:86:11-14.

13 Barlow S, Dietz WH. Obesity evaluation and treatment: expert committee recommendations. Pediatrics 1998;102(3). URL: www.pediatrics.org/cgi/content/full/102/3/e29.

14 Reilly JJ, Dorosty AR, Emmett PM, and the ALSPAC Study Team Identification of the obese child: adequacy of the BMI for clinical practice and epidemiology. Int J Obes 2000;24:1623-7.

15 Dietz WH. Health consequences of obesity in youth: childhood predictors of adult disease. Pediatrics 1998;101:518-25.

16 Whitaker RC, Wright JA, Pepe MS, et al. Predicting obesity in young adulthood from childhood and parental obesity. N Engl J Med 1997;337:869-73

17 Freedman DS, Dietz WH, Srinivasan SR, et al. The relation of overweight to cardiovascular risk factors among children and adolescents: the Bogalusa Heart Study. Pediatrics 1999;103:1 175-82.

18 Morrison JA, Barton BA, Biro FM, et al. Overweight, fat patterning, and cardiovascular disease risk factors in black and white boys. J Pediatr 1999;135:451-7.

19 Morrison JA, Sprecker DL, Barton BA, et al. Overweight, fat patterning, and cardiovascular disease risk factors in black and white girls. J Pediatr 1999; 135:458-64.

20 Cole TJ, Bellizzi MC, Flegal KM, et al. Establishing a standard definition for child overweight and obesity worldwide: international survey. BM 2000;320: 1240-4.

21 Reilly JJ. Assessment of childhood obesity using the body mass index: national reference data or "international" approach? Obes Res. In press.

22 Kinra S, Nelder RP, Lewendon GJ. Deprivation and childhood obesity: a cross-sectional study of 20,973 children in Plymouth, UK. J Epidemiol Community Health 2000;54:456-60.

23 Sahota P, Rudolf MC, Dixey R, et al. Randomised controlled trial of primary school based intervention to reduce risk factors for obesity. BM $2001 ; 323: 1-5$

\section{IMAGES IN PAEDIATRICS.}

\section{Late presentation of congenital diaphragmatic hernia}

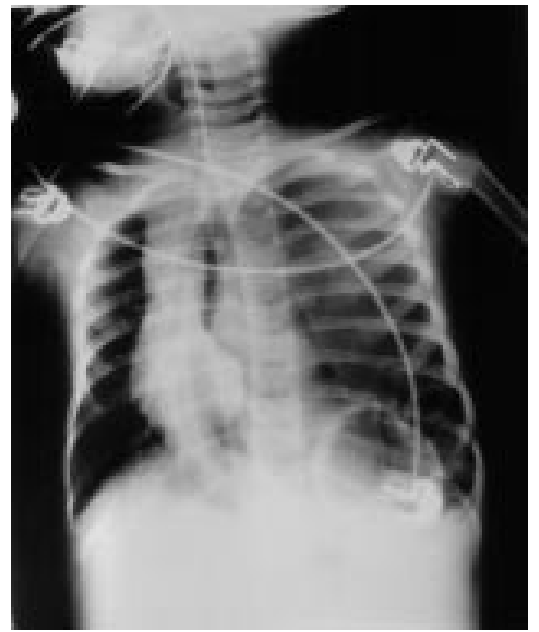

Figure 1 Chest $x$ ray showing a large left sided tension pneumothorax with the appearance of gastric bubble above the diaphragm. ongenital diaphragmatic hernia (CDH) presents most frequently in the newborn period with neonates exhibiting severe respiratory distress. However, a proportion (estimated to be between $5 \%$ to $30 \%^{1}$ ) present beyond the neonatal period.

We report a case of an 18 month old child who presented with acute tension pneumothorax. The previously healthy 18 month old boy, who had had an uneventful neonatal period, was admitted with a two day history of cough and vomiting. He was febrile, poorly perfused, tachypnoeic, and unresponsive. He was resuscitated and intubated. Chest $x$ ray (fig l) showed a large left pneumothorax, with mediastinal shift and gastric or intestinal air bubble above the diaphragm. A chest drain was inserted, releasing air and dark brown fluid. Microscopy revealed a mixture of Gram positive and negative cocci and bacilli, implying gastrointestinal perforation. He was transferred to the paediatric intensive care unit with a provisional diagnosis of strangulated congenital diaphragmatic hernia. This was confirmed at laparotomy with perforation secondary to ischaemia. Stomach, colon, and spleen were reduced from the left hemithorax and a gastric perforation repaired. The child made a satisfactory postoperative recovery.

With an incidence of 1 in 3000 live births, congenital diaphragmatic hernia is relatively common. However, this diagnosis is often not considered after the neonatal period. CDH should be considered in any infant or child presenting with respiratory symptoms, particularly where the chest $x$ ray shows a poorly defined diaphragm and cystic lesion on their chest $x$ ray film. ${ }^{2}$

\section{P O'Neill \\ R Mabrouk \\ W A McCallion}

Paediatric Intensive Care Unit, Royal Belfast Hospital For Sick Children, Falls Road, Belfast BT12 6BE, UK; conoroneill@doctorsnet.org.uk

\section{References}

1 Gleeson F, Spitz L. Piffalls in the diagnosis of congenital diaphragmatic hernia. Arch Dis Child 1991;66:670-1.

2 Booker PD, Meerstadt PW, Bush GH. Congenital diaphragmatic hernia in the older child. Arch Dis Child 1981;56:253-7. 